\title{
Técnica para injeção intravítrea de drogas no tratamento de doenças vítreorretinianas
}

\author{
Technique of intravitreal drug injection for therapy of vitreoretinal diseases
}

\author{
Eduardo Buchele Rodrigues ${ }^{1}$ \\ Mauricio Maia $^{2}$ \\ Fernando Marcondes Penha ${ }^{3}$ \\ Eduardo Dib ${ }^{4}$ \\ ArnaldoFurman Bordon 5 \\ Octaviano Magalhães Júnior ${ }^{6}$ \\ Michel Eid Farah ${ }^{7}$
}

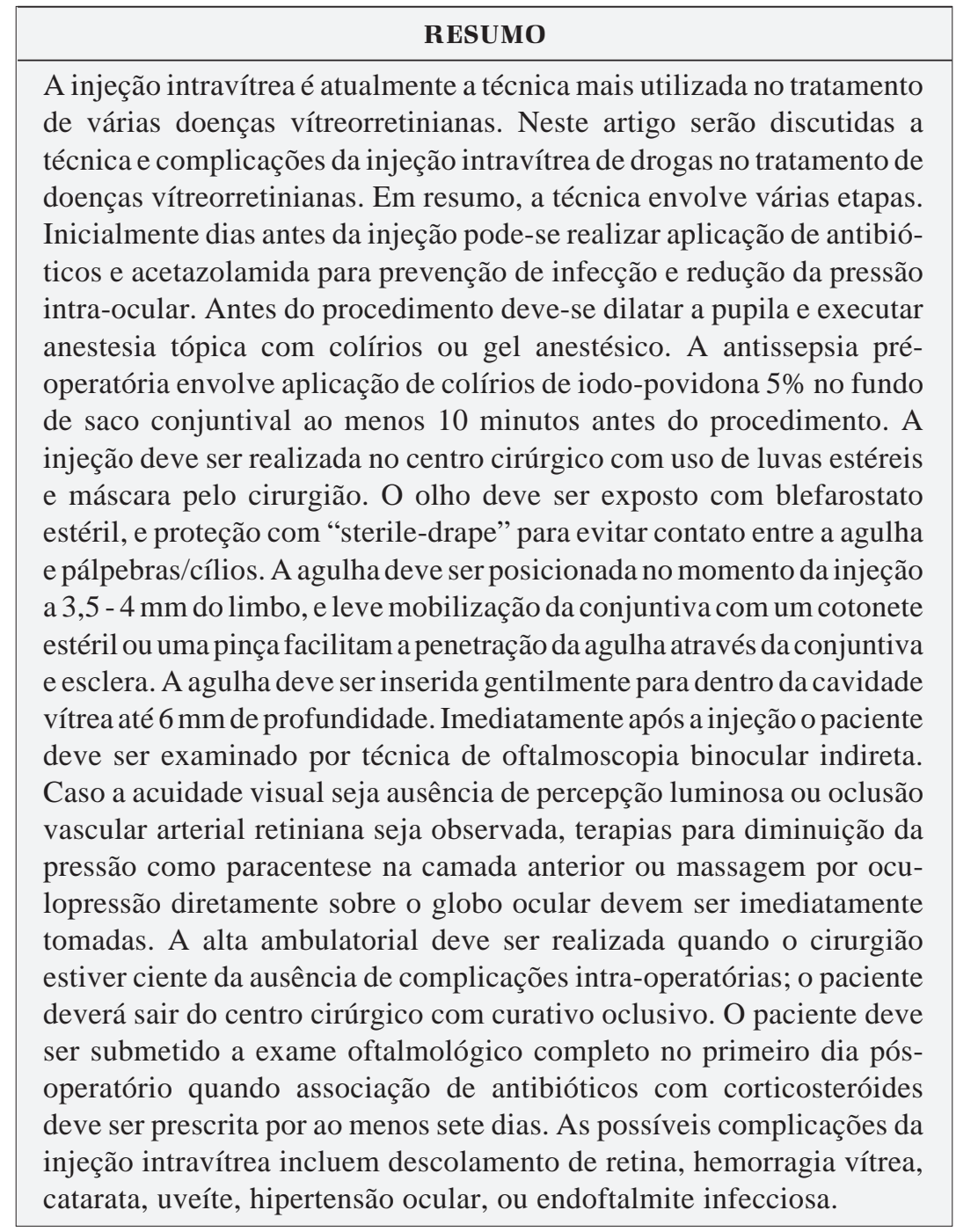

Descritores: Degeneração macular; Efeito idade; Retina; Fator de crescimento endotelial vascular; Cegueira; Injeção intravítrea

\section{INTRODUÇÃO}

O tratamento farmacológico de doenças vítreorretianas é uma importante modalidade terapêutica em oftalmologia e, em especial, no tratamento de doenças retinianas como a degeneração macular relacionada à idade ${ }^{(1-3)}$. O desenvolvimento de medicamentos para a aplicação intra-ocular é uma área 
em expansão, que tem atraído grande investimento da indústria farmacêutica. O olho oferece uma situação privilegiada para a farmacoterapia, pois é um órgão exposto de fácil acesso cirúrgico e tem uma farmacocinética relativamente bem estudada. A aplicação ocular do fármaco minimiza a sua absorção sistêmica, evitando-se assim as eventuais complicações associadas ao uso sistêmico. As diversas vias de acesso para a aplicação de agentes farmacológicos, na terapia de doenças da retina, incluem a injeção justa-escleral, a inserção de implantes intra-oculares, e a injeção intravítrea de drogas ${ }^{(4)}$. A injeção intravítrea é a técnica mais difundida, no momento, devido a sua menor complexidade e maior precisão em fornecer quantidades significativas de drogas aplicadas diretamente sobre o tecido retiniano. Algumas das desvantagens da injeção intravítrea são os riscos inerentes ao procedimento em si, incluindo a endoftalmite, a toxicidade ocular e retiniana do fármaco, e a curta meia-vida intra-ocular de muitas das drogas disponíveis para uso intravítreo ${ }^{(5-6)}$.

Neste artigo serão discutidas as técnicas e complicações da injeção intravítrea de drogas no tratamento de doenças vitreorretinianas. No dia $1^{\circ}$ de março de 2007, foi realizado o primeiro curso de injeções intravítreas do Simpósio de Oftalmologia do Departamento de Oftalmologia/Instituto da Visão da UNIFESP. As principais conclusões deste curso de injeções intravítreas, os principais dados da literatura científica, e algumas observações da experiência dos autores serão utilizados como referência neste trabalho.

\section{Preparação pré-injeção}

A preparação deve ser preferencialmente realizada em ambiente com filtro de ar, ou seja, no centro cirúrgico, apesar de alguns autores admitirem que a aplicação dentro do consultório médico também seja confiável.

A profilaxia contra infecções intra-oculares e a redução da pressão intra-ocular é um tema bastante controverso na literatura. O uso de antibióticos tópicos, três dias antes da injeção intravítrea, pode oferecer redução da flora bacteriana conjuntival, eliminar os germes mais virulentos e ainda penetrar na câmara anterior. Entretanto, até o momento, não há evidências clínicas suficientes que dêem suporte para esse uso profilático de antibióticos ${ }^{(7)}$. Estudos experimentais demonstraram maior índice de infecção nos grupos não tratados previamente com antibióticos ${ }^{(8-9)}$. Além disso, o uso de colírios antibióticos pré-operatórios tem sido realizado em vários protocolos de estudos clínicos multicêntricos, e na prática clínica diária de $61,8 \%$ dos entrevistados, no "Preferences and Trends Survey 2006" - entre os membros da "American Society of Retina Specialists"(10-11). Algumas desvantagens dessa técnica são: o aumento no custo do tratamento, propício ao surgimento de cepas microbiológicas resistentes, além de retardar o início da terapia farmacológica em caso de infecções. Em resumo, até o momento, não há estudos randomizados, controlados, que comprovem a diminuição da incidência de endoftalmites com o uso pré-operatório de antibióticos tópicos. Caso este seja utilizado, recomenda-se o uso de uma quinolona de quarta geração, a cada seis horas, três dias antes do procedimento, por apresentar um maior espectro de ação, boa penetração na câmara anterior e menor resistência in vitro a outras quinolonas, como ciprofloxacino e ofloxacino.

Outro assunto controverso relacionado ao preparo préinjeção é a diminuição da pressão intra-ocular. Algumas técnicas podem ser utilizadas com esse objetivo, entre elas, o uso de hipotensores tópicos e/ou sistêmicos e manobras hipotensoras compressivas como a manobra de Chandler (massagem bidigital). A acetazolamida, via oral, reduz substancialmente a pressão intra-ocular e, eventualmente, pode ser prescrita, horas ou poucos dias antes do procedimento, para pacientes com escavação aumentada do nervo óptico ou glaucoma estabelecido $^{(5)}$. Entretanto, esta não deve ser uma prática habitual, considerando os efeitos colaterais da droga, como hipocalemia, sintomas gastrintestinais, gosto metálico, e precipitação de crises de falcização em pacientes com anemia falciforme. A massagem bidigital é uma prática freqüente em diversos "Clinical Trials", como o Vitrase e Vitravene, e também na prática diária de vários oftalmologistas ${ }^{(5)}$. Porém, a manipulação palpebral e, conseqüentemente, das glândulas de meibômio aumentam o risco de infecções. Se a opção for pela massagem, recomenda-se que a pressão deva ser exercida diretamente no globo ocular, evitando a manipulação palpebral. O mesmo raciocínio serve para o balão de Honan, que apesar de diminuir, significativamente, a pressão intra-ocular, também envolve a manipulação palpebral e o aumento teórico do risco de endoftalmite.

\section{Midríase medicamentosa e anestesia tópica}

Para a visualização do fundo de olho após a injeção, a pupila deve ser dilatada, desde que não haja contra-indicações para tal fim. A anestesia pode ser tópica, usando colírios, gel ou bloqueio peribulbar. Para a obtenção de uma anestesia adequada tópica, inicia-se a aplicação de gotas anestésicas ao menos dez minutos antes do procedimento; aplica-se uma gota a cada três minutos, aproximadamente. Recomenda-se a utilização de frascos novos de colírios para prevenir infecções ${ }^{(12-13)}$. Uma alternativa para a anestesia tópica é a injeção subconjuntival de lidocaína a $2 \%$ ou o uso de gel anestésico de lidocaína a $2 \%$. O bloqueio peribulbar e/ou sedação pode ser utilizado em casos de pacientes que não cooperem com a imobilização do globo ocular, embora isso ocorra raramente.

\section{Anti-sepsia ocular pré-operatória}

A principal origem de endoftalmite pós-operatória infecciosa é a flora local dos tecidos perioculares e anexos, como conjuntiva e pálpebra ${ }^{(7,14-15)}$. Em aproximadamente $80 \%$ dos casos de endoftalmite pós-operatória, o mesmo agente infeccioso foi identificado com testes genéticos na pálpebra, na conjuntiva ou nariz, e estes são Staphylococcus epidermidis ou Staphylococcus aureus ${ }^{(16)}$. Baseado nesses dados, a aplicação de medidas profiláticas antibacterianas com iodo-povidona 5\% está altamente justificada. Alguns estudos preconizam o uso pré-operatório de antibióticos tópicos - 3 dias antes da 
injeção - associado a iodo-povidona tópico, para diminuir a chance de infecção ${ }^{(5)}$. Recomenda-se a limpeza mecânica dos cílios, da pálpebra, e da pele palpebral, com solução de iodopovidona a $10 \%$. Enquanto a maioria dos estudos sugere a aplicação de uma gota de iodo-povidona 5\%, ao menos 3 minutos antes da injeção, pode-se também pingar o anti-séptico, antes de 3 minutos, por várias vezes. A vantagem desta última técnica seria uma maior concentração do anti-séptico, para a diminuição da flora conjuntiva. No entanto, o uso indiscriminado de iodo-povidona pode lesar o epitélio corneano. Ao menos 10 minutos antes da injeção, várias gotas de iodo-povidona a $5 \%$ devem ser aplicadas no saco conjuntival para evitar lesão corneana; eventualmente, pode-se irrigar a conjuntiva, fórnix e carúncula com a solução anti-séptica ${ }^{(17)}$. Esta solução de iodo-povidona de 5\% deposita-se na membrana celular, exercendo ação bactericida para a maioria das bactérias, vírus e esporos $^{(12,15)}$. A massagem nas pálpebras, para a extrusão de secreção das glândulas palpebrais, ou colocação de pesos redutores da pressão intra-ocular, devem ser evitados ${ }^{(5)}$.

\section{Esterilização e anti-sepsia do material cirúrgico e dos profissionais de saúde}

Além das medidas para a eliminação das bactérias nativas dos pacientes, cuidados com a desinfecção das mãos, a preparação do campo operatório, e a utilização de seringas e cânulas esterilizadas são recomendadas ${ }^{(12,18-19)}$. Preferencialmente, o cirurgião deverá realizar a escovação tradicional e utilizar luvas estéreis para a aplicação da injeção intravítrea, assim como deverá usar a máscara para a cobertura das vias aéreas. O olho deve ser exposto com blefarostato estéril. A proteção com "sterile-drape" deve ser utilizada para evitar o contato entre a agulha e as pálpebras/cílios ${ }^{(12)}$. Ao menos uma gota de iodopovidona $5 \%$ deve ser aplicada, após o posicionamento do blefarostato e imediatamente antes da penetração da agulha (Figura 1).

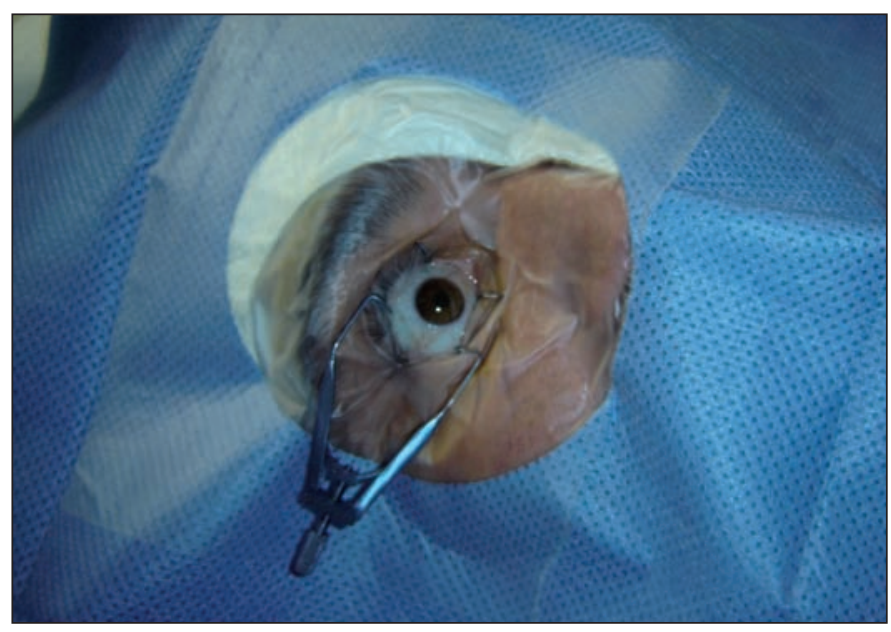

Figura 1 - Paciente posicionado no centro cirúrgico para ser submetido a injeção intravitrea. Cuidados de antissepsia e esterilização devem ser tomados. O olho deve ser exposto com blefarostato estéril, e proteção com "sterile-drape" para evitar contato entre a agulha e pálpebras/cílios.

\section{Execução da injeção}

O procedimento deve ser realizado preferencialmente sob o microscópio cirúrgico. No momento da injeção, a agulha deve ser posicionada a 3-3,5 mm do limbo e tentar, ao mesmo tempo, a mobilização da conjuntiva com um cotonete estéril ou uma pinça, a fỉm de facilitar a penetração da agulha através da conjuntiva e esclera, por um plano único ${ }^{(5)}$. O desalinhamento do orifício da conjuntiva com o orifício da esclera pode ser utilizado por diminuir, teoricamente, o risco de refluxo do conteúdo intra-ocular, embora não haja comprovação na literatura científica. A fixação do globo ocular com pinça pode evitar movimentos bruscos laterais e diminuir a ocorrência de toque do cristalino durante a penetração da agulha. Esta deve ser de pequeno diâmetro, de 26, 27, 29 ou 30 gauge; de preferência, menor que 27 gauge $^{(5)}$. Recomenda-se que a injeção seja realizada nos quadrantes temporal inferior ou temporal superior ${ }^{(5)}$. Antes da aplicação do medicamento, ainda é discutível a necessidade de verificação da ponta da agulha dentro da cavidade vítrea. A agulha deve ser inserida, gentilmente, para dentro da cavidade vítrea até $6 \mathrm{~mm}$ de profundidade; injeção rápida pode levar à dispersão excessiva da droga, desprendimento da agulha, e roturas retinianas.

Recentemente, introduzimos o uso de uma incisão escleral em túnel, que pode ser utilizada para prevenir o refluxo vítreo $^{(20)}$. A oclusão da esclerotomia imediatamente após a injeção é recomendável, a fim de evitar o refluxo de medicamento ou prolapso do vítreo ${ }^{(12)}$.

\section{Verificação da acuidade visual e exame com oftalmoscópio indireto}

Imediatamente após a injeção, o paciente dever ser examinado por técnica de oftalmoscopia binocular indireta, para a verificação da perfusão da artéria central da retina, o posicionamento do medicamento, além de observar a exclusão de complicações como o deslocamento da retina, a catarata traumática ou hemorragia vítrea. $\mathrm{O}$ exame do fundo de olho imediato, no pós-operatório, oferece a possibilidade do tratamento precoce de complicações graves intra-oculares ${ }^{(5,12)}$. A acuidade visual no olho injetado deve ser melhor que percepção luminosa, confirmando a perfusão arterial retiniana normal. Caso a acuidade visual seja a ausência de percepção luminosa ou a oclusão vascular arterial retiniana seja observada - terapias para a diminuição da pressão, como paracentese na câmara anterior ou massagem por óculopressão diretamente sobre o globo ocular, devem ser imediatamente providenciadas.

\section{Medida da pressão intra-ocular}

Recomenda-se a realização de tonometria de aplanação após, aproximadamente, 30 a 60 minutos da injeção intravítrea. Caso o aumento da pressão intra-ocular seja evidenciado, pode-se solicitar que o paciente tome um ou dois comprimidos de acetazolamida, via oral, ou faça terapia com colírios tópi$\cos ^{(5)}$. Outra medida que pode ser adotada nos casos em que o aumento agudo da pressão intra-ocular ameaçe a visão, é o tratamento cirúrgico com paracentese da câmara anterior ${ }^{(5)}$. 
Esta medida geralmente é realizada apenas em casos necessários, considerando o risco aumentado de endoftalmites com o procedimento $^{(5)}$.

\section{Orientação e alta ambulatorial}

A alta ambulatorial deve ser realizada quando o cirurgião estiver ciente da ausência de complicações intra-operatórias; o paciente deverá sair do centro cirúrgico com o curativo oclusivo. O paciente deve ser orientado dos sintomas relacionados ao aumento da pressão intra-ocular, descolamento de retina ou hemorragia vítrea. Alguns movimentos de risco como o ato de coçar o olho, carregar excesso de peso, assim como a manobra de Valsalva devem ser evitados pelo paciente nos primeiros dias após a injeção intravítrea de fármacos. O paciente deve ser submetido a exame oftalmológico completo no primeiro dia pósoperatório, quando a associação de antibióticos com corticosteróides deve ser prescrita por ao menos sete dias, apesar de não haver ainda consenso de qual antibiótico é mais recomendável para a profilaxia. Eventualmente, medicação antiglaucomatosa se houver o aumento da pressão intra-ocular. Novo exame de controle pode ser realizado, em aproximadamente sete dias, para a exclusão de endoftalmite. A figura 2 resume os passos na técnica de injeções intravítreas.

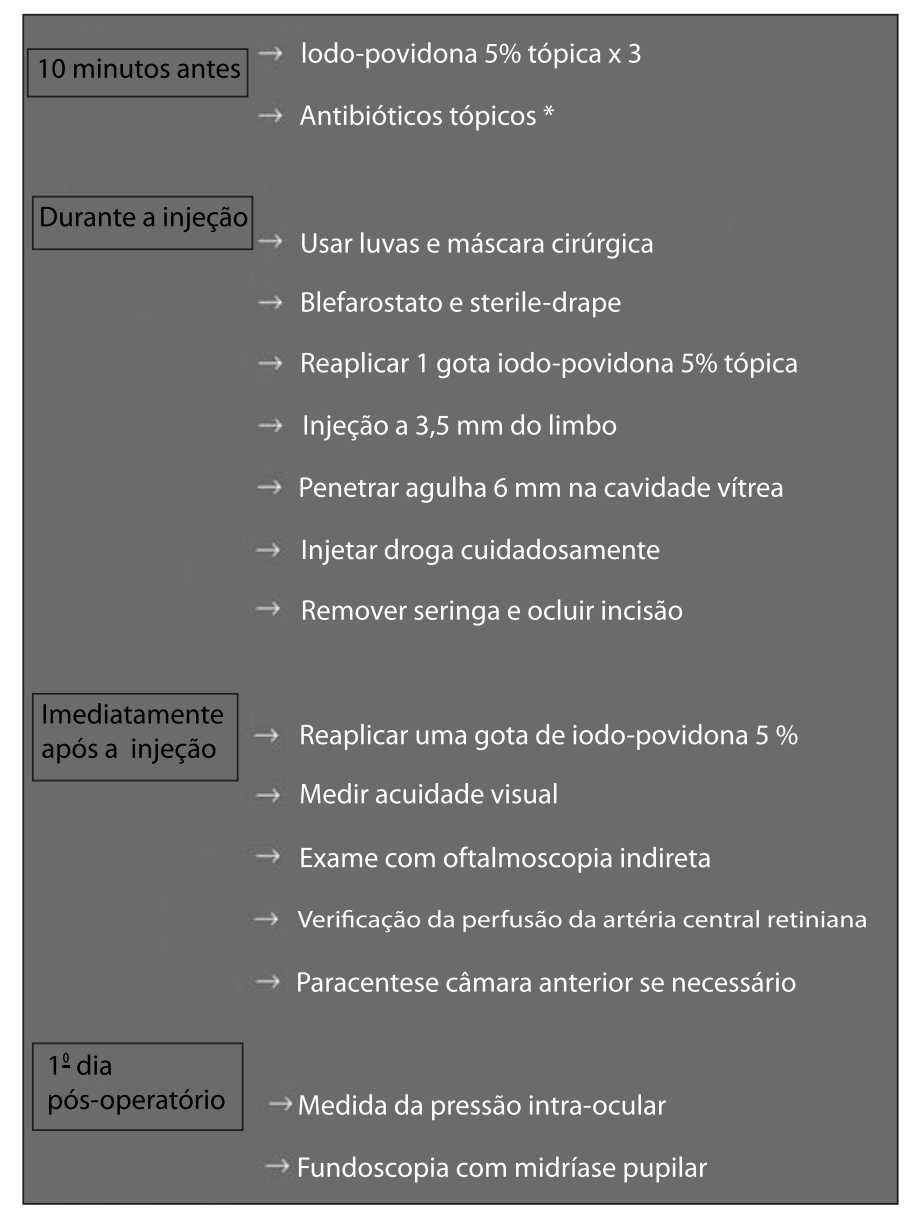

Figura 2 - Passos cirúrgicos na técnica de injeção intravítrea

\section{Complicações associadas à injeção intravítrea de medicamentos}

A identificação de fatores de risco e potenciais complicações na aplicação de drogas intravítreas constitui em um importante aspecto na farmacoterapia de doenças retinianas. Algumas das principais complicações, relacionadas à injeção intravítrea de drogas, incluem descolamento de retina, hemorragia vítrea, catarata, uveíte, hipertensão ocular ou endoftalmite infecciosa.

\section{Endoftalmite}

A prevalência de endoftalmite infecciosa, em uma revisão de 15.000 injeções, foi de aproximadamente $0,9 \%$ por olho e $0,3 \%$ por injeção ${ }^{(5,12)}$. Curiosamente, a prevalência de endoftalmite foi maior nos pacientes tratados com acetonido de triancinolona em comparação com outras drogas; técnicas cirúrgicas com medidas preventivas oferecem redução significativa na taxa de endoftalmite ${ }^{(5)}$. Fatores predisponentes ao surgimento de endoftalmite consistem em má preparação antiséptica pré-operatória, infecção ocular externa, história de diabetes, presença de bolhas filtrantes anti-glaucomatosa, infecção das vias aéreas superiores, imunossupressão sistêmica, uso crônico de lentes de contato, e injeção a partir de drogas oriundas de frascos de re-utilizados ${ }^{(21-24)}$. As fontes de bactérias para o surgimento de endoftalmite situam-se na conjuntiva, cílios e margem palpebral. Para a prevenção desta complicação, as infecções de tecidos extra-oculares com blefarite, hordéolo, ou conjuntivite devem ser tratadas antes da injeção intravítrea. Adicionalmente, pacientes com defeitos no fechamento palpebral, assim como aqueles com imunossupressão endógena ou exógena devem ter a injeção intravítrea adiada ${ }^{(12)}$.

\section{Descolamento de retina}

Descolamento de retina é uma complicação rara, mas temível após injeção intravítrea. A prevalência desta complicação situase em aproximadamente $3 \%$ por olho e $0,5 \%$ por injeção ${ }^{(5,13)}$. No entanto, dentro desta casuística foram incluídos os descolamentos provavelmente associados à condição predisponente como retinite por citomegalovirus ou RD proliferativa. Em pacientes sem doenças predisponentes, a incidência dessa complicação encontra-se em níveis menores ${ }^{(13)}$.

\section{Hemorragia intra-ocular}

Hemorragia vítrea é uma rara complicação e de incidência difícil de ser determinada, mas estima-se que gire em torno de $1 \%$ por injeção. A hemorragia pode ocorrer devido às doençasbase, mas em alguns casos pode surgir pela rotura de pequenos vasos retinianos decorrente do aumento súbito da pressão intra-ocular ou pela presença de volume líquido intravítreo.

\section{Hipertensão ocular}

O aumento da pressão intra-ocular pode ocorrer transitoriamente ou persistentemente após a farmacoterapia intravítrea. Enquanto o aumento da pressão transitória é um fenôme- 
no freqüente, a hipertensão ocular persistente ocorre em aproximadamente $2 \%$ dos pacientes tratados com a medicação intravítrea (com exceção de triancinolona), podendo induzir oclusão da artéria central da retina e cegueira permanente ${ }^{(13)}$. O aumento da pressão intra-ocular, após injeção intravítrea, pode ser causado pelo aumento do volume intra-ocular ou pelas características da droga específica injetada, como os corticosteróides ${ }^{(25)}$. O aumento da pressão ocular, após injeção de AT, pode ocorrer em até $38 \%$ dos pacientes e, na maioria das vezes, é controlado com uso de colírios tópicos ${ }^{(5)}$. Portanto, a injeção intravítrea de medicamentos e, em especial de corticosteróides, devem ser cuidadosamente analisada em pacientes com glaucoma em estágio avançado.

\section{Inflamação dos tecidos intra-oculares}

A inflamação ocular secundária manifesta-se clinicamente como uveíte anterior ou posterior, com ou sem pseudohipópio. A prevalência de inflamação intra-ocular, após injeção intravítrea, de vários agentes farmacológicos gira em torno de $1 \%{ }^{(13)}$. Em trabalhos que incluem drogas como cidofovir, fomivirsen ou hialorunidase a frequiência desta complicação pode subir até $40 \%{ }^{(26)}$. A introdução recente dos anticorpos monoclonais com proteínas não-humanas murinas e aptâmeros anti-VEGF pode aumentar a incidência de uveíte após injeção intravítrea de fármacos; o mecanismo mais provável é a produção de anticorpos contra proteínas "nonself". O maior desafio na clínica diária desta entidade é sua diferenciação com endoftalmite.

\section{Catarata}

Catarata consiste em uma complicação decorrente do medicamento propriamente, ou traumática pelo toque ou penetração mecânica da agulha no cristalino. Apesar de alguns estudos mostrarem uma incidência muito baixa de opacificação do cristalino, após injeção intravítrea, ou uso de triancinolona, fomivirsen, cidofovir, ou metotrexate aumenta substancialmente o surgimento desta complicação. A prevalência de catarata com o uso de triancinolona gira em torno de 20$40 \%$ por olho injetado após 1 ano de seguimento dos pacientes em ensaio clínico randomizado ${ }^{(27)}$, apesar de que até $73 \%$ dos olhos que receberam múltiplas injeções do medicamento metrotrexate evoluíram com esclrerose nuclear ${ }^{(28)}$. A real incidência de catarata após injeção intravítrea é de difícil avaliação devido às modificações sutis da opacidade da lente e ao fato de grande parte dos pacientes encontrar-se na faixa etária típica de desenvolvimento de catarata ${ }^{(29)}$.

\section{CONCLUSÃO}

A técnica de injeção intravítrea estabeleceu-se como um procedimento minimamente invasivo para o tratamento de doenças da mácula como degeneração macular neovascular e retinopatia diabética. Com o surgimento de vários agentes terapêuticos anti-angiogênicos como pegaptanibe, ranibizu- mabe e bevacizumabe, a técnica de administração intravítrea ganha mais importância na terapêutica oftalmológica. Essa técnica envolve potenciais complicações, mas que são, em sua grande maioria, passíveis de prevenção. O uso de técnica adequada e cuidados pré e pós-operatórios devem minimizar os riscos de injeções intravítreas e complicações como endoftalmite ou descolamento de retina. Os avanços na técnica de injeção intravítrea devem diminuir a incidência de complicações e melhorar a eficácia dessa abordagem ${ }^{(30-31)}$.

\section{ABSTRACT}

Intravitreal injections are the standard technique applied in the treatment of some vitreoretinal diseases. In this paper the technique and complications of intravitreal injections are presented. In summary, the procedure involves various consecutive steps. Initially, days before the treatment topical antibiotics and acetazolamide may be prescribed for reduction of the ocular flora and intraocular pressure. Before the injection, the pupil should be dilated and topical anesthesia should be achieved. Injection shall be performed in the operating room under sterile conditions, the surgeon should wear surgical gloves and mask. The eye is then exposed with sterile blepharostat and sterile-drape thereby providing protection of the needle against the contact with contaminated lashes and lids. Injection is done $3.5 \mathrm{~mm}$ from the limbus through the pars plana. The needle should be inserted up to $6 \mathrm{~mm}$ into the vitreous cavity. Immediately after injection the patient must be examined by indirect ophthalmoscopy to verify central artery perfusion and complications as vitreous hemorrhage. Visual acuity better than light perception should be detected right after injection. If persistent central retinal artery occlusion is diagnosed, anterior chamber paracentesis should be performed. The patient may be discharged with an occlusive patch. Examination at the first postoperative day should exclude various complications such as endophthalmitis, and topical steroid and antibiotics should be prescribed for 7 days. Some complications encountered after intravitreal injections include retinal detachment, vitreous hemorrhage, cataract, uveitis, ocular hypertension, or endophthalmitis.

Keywords: Macular degeneration; Age effect; Retina; Vascular endothelial growth factor; Blindness; Intravitreal injection

\section{REFERÊNCIAS}

1. Rodrigues EB, Rossi EM, Grumann Júnior A, Meyer CH, Ho AC. Tratamento da forma neovascular de degeneração macular relacionada à idade com drogas antiangiogênicas. Arq Bras Oftalmol. 2006;69(5):756-65.

2. Oliveira Neto H, Bordon AF, Farah ME, Breuer M, Uno F. Estudo e classificação das membranas neovasculares subretinianas na degeneração macular relacionada à idade pela angiografia digital com indocianina verde. Arq Bras Oftalmol. 1998;61(3):312-22.

3. Farah ME, Oshima A, Costa RA, Sallum JF. Degeneração macular relacionada à idade: modalidades terapêuticas. Arq Bras Oftalmol. 2001;64(6):583-8.

4. Kurz D, Ciulla TA. Novel approaches for retinal drug delivery. Ophthalmol Clin North Am. 2002;15(3):405-10. Review. 
5. Aiello LP, Brucker AJ, Chang S, Cunningham ET Jr, D'Amico DJ, Flynn HW Jr, et al. Evolving guidelines for intravitreous injections. Retina. 2004; 24(Suppl 5):S3-19. Review.

6. Jaissle GB, Szurman P, Bartz-Schmidt KU; German Retina Society; German Society of Ophthalmology; German Professional Association of Ophthalmologists. [Recommendation for the implementation of intravitreal injections statement of the German Retina Society, the German Society of Ophthalmology (DOG) and the German Professional Association of Ophthalmologists (BVA)]. Klin Monatsbl Augenheilkd. 2005;222(5):390-5. German.

7. Ta CN. Minimizing the risk of endophthalmitis following intravitreous injections. Retina. 2004;24(5):699-705.

8. Bucher RS, Hall E, Reed DM, Richards JE, Johnson MW, Zacks DN. Effect of intravitreal triamcinolone acetonide on susceptibility to experimental bacterial endophthalmitis and subsequent response to treatment. Arch Ophthalmol. 2005; 123(5):649-53.

9. Bucher RS, Johnson MW. Microbiologic studies of multiple-dose containers of triamcinolone acetonide and lidocaine hydrochloride. Retina. 2005;25(3):269-71.

10. Bylsma G, Guymer R, Qureshi S, Gin T, Allen P, Madhok P, et al. Intravitreous injections. Clin Experiment Ophthalmol. 2006;34(4):388-90.

11. Scott IU, Flynn HW Jr. The role of topical antibiotic prophylaxis for intravitreal injections. Arch Ophthalmol. 2007;125(7):974-6.

12. Jaissle GB, Bartz-Schmidt KU. [Intravitreal injections - high standard of the procedure necessary]. Klin Monatsbl Augenheilkd. 2005;222(5):389. German.

13. Jager RD, Aiello LP, Patel SC, Cunningham ET Jr. Risks of intravitreous injection: a comprehensive review. Retina. 2004;24(5):676-98.

14. Ciulla TA, Starr MB, Masket S. Bacterial endophthalmitis prophylaxis for cataract surgery: an evidence-based update. Ophthalmology. 2002;109(1):13-24. Comment in: Ophthalmology. 2003;110(8):1667; author reply 1667-8. Ophthalmology. 2003;110(8):1668; author reply 1669.

15. Apt L, Isenberg S, Yoshimori R, Paez JH. Chemical preparation of the eye in ophthalmic surgery. III. Effect of povidone-iodine on the conjunctiva. Arch Ophthalmol. 1984;102(5):728-9.

16. Speaker MG, Menikoff JA. Prophylaxis of endophthalmitis with topical povidone-iodine. Ophthalmology. 1991;98(12):1769-75

17. Hanscom TA. Postoperative endophthalmitis. Clin Infect Dis. 2004;38(4):542-6.

18. Mamalis N, Kearsley L, Brinton E. Postoperative endophthalmitis. Curr Opin Ophthalmol. 2002;13(1):14-8.
19. Perry LD, Skaggs C. Preoperative topical antibiotics and lash trimming in cataract surgery. Ophthalmic Surg. 1977;8(5):44-8.

20. Rodrigues EB, Meyer CH, Grumann A Jr, Shiroma H, Aguni JS, Farah ME Tunneled scleral incision to prevent vitreal reflux after intravitreal injection. Am J Ophthalmol. 2007;143(6):1035-7.

21. Moshfeghi DM, Kaiser PK, Scott IU, Sears JE, Benz M, Sinesterra JP, et al. Acute endophthalmitis following intravitreal triamcinolone acetonide injection. Am J Ophthalmol. 2003;136(5):791-6.

22. Doft BH, Wisniewski SR, Kelsey SF, Groer-Fitzgerald S; Endophthalmitis Vitrectomy Study Group. Diabetes and postcataract extraction endophthalmitis. Curr Opin Ophthalmol. 2002;13(3):147-51.

23. Song A, Scott IU, Flynn HW Jr, Budenz DL. Delayed-onset bleb-associated endophthalmitis: clinical features and visual acuity outcomes. Ophthalmology. 2002;109(5):985-91.

24. Kresloff MS, Castellarin AA, Zarbin MA. Endophthalmitis. Surv Ophthalmol. 1998;43(3):193-224. Review.

25. Jonas JB, Kreissig I, Degenring R. Intraocular pressure after intravitreal injection of triamcinolone acetonide. Br J Ophthalmol. 2003;87(1):24-7.

26. Young S, Morlet N, Besen G, Wiley CA, Jones P, Gold J, et al. High-dose (2000-microgram) intravitreous ganciclovir in the treatment of cytomegalovirus retinitis. Ophthalmology. 1998;105(8):1404-10.

27. Sutter FK, Simpson JM, Gillies MC. Intravitreal triamcinolone for diabetic macular edema that persists after laser treatment: three-month efficacy and safety results of a prospective, randomized, double-masked, placebo-controlled clinical trial. Ophthalmology. 2004;111(11):2044-9.

28. Smith JR, Rosenbaum JT, Wilson DJ, Doolittle ND, Siegal T, Neuwelt EA, Pe'er J. Role of intravitreal methotrexate in the management of primary central nervous system lymphoma with ocular involvement. Ophthalmology. 2002; 109(9):1709-16.

29. Korobelnik JF, Cochereau I, Cohen SY, Coscas G, Creuzot-Garcher C, Devin F, et al. [How to perform intravitreal injections]. J Fr Ophtalmol. 2006;29(1): 82-6. French.

30. Pulido JS, Zobitz ME, An KN. Scleral penetration force requirements for commonly used intravitreal needles. Eye. 2007;21(9):1210-1.

31. Pulido JS, Pulido CM, Bakri SJ, McCannel CA, Cameron JD. The use of 31-gauge needles and syringes for intraocular injections. Eye. 2007;21(6): 829-30. 